\title{
MANAJEMEN PERUBAHAN DALAM PARADIGMA PENGEMBANGAN SUMBER DAYA MANUSIA GUNA MENDUKUNG KEUNGGULAN KOMPETITIF ORGANISASI
}

\author{
CHANGES MANAGEMENT IN THE PARADIGM OF HUMAN RESOURCE \\ DEVELOPMENT TO SUPPORT COMPETITIVE ADVANTAGE ORGANIZATION
}

\author{
Teguh Narutomo \\ Pusat Penelitian dan Pengembangan Kesatuan Bangsa, Politik dan Otonomi Daerah \\ Badan Penelitian dan Pengembangan (BPP) Kementerian Dalam Negeri \\ Jl. Kramat Raya No. 132 - Senen, Jakarta \\ Nomor Telp./Faks: +62 21314 0454; e-mail: narutomo_litbang@yahoo.com \\ Diterima: 16 Januari 2012, Direvisi: 23 Februari 2012, Disetujui: 27 Februari 2012
}

\begin{abstract}
Abstrak
Perkembangan dunia yang sangat cepat menuntut persaingan di semua sektor yang semakin ketat. Untuk dapat mengungguli pesaingnya, setiap organisasi harus memiliki keunggulan kompetitif tertentu. Keunggulan ini dapat dibentuk melalui penciptakan produk dengan desain yang unik, penggunaan teknologi modern, dan yang paling strategis adalah manajemen sumber daya manusia yang efektif. Tulisan ini bertujuan memberikan memaparkan hubungan erat antara perubahan pola manajemen sumber daya manusia dengan keunggulan kompetitif suatu organisasi. Dalam konteks perubahan pola manajemen sumber daya manusia ini, peran pimpinan sangat strategis guna meningkatkan potensi sumber daya manusia agar berdayaguna secara optimal untuk meningkatkan kinerja organisasi, sehingga organisasi mampu memiliki keuanggulan kompetitif.

Kata Kunci: manajemen, sumber daya manusia, organisasi
\end{abstract}

\begin{abstract}
Competition among business become more intense as the business world quickly changes. To win the competition, every organization, public or private sector should have a competitive advantage. This advantage can be established through various means, such as creating a product with unique design, using of modern technology, and most importantly applying the management of human resources effectively. This article aims to descript the direct relationship between the shift of human resources management pattern and competitive advantage of organization. In the context of human resource management, leadership needs to increase the range of potential human resources in order to be able to empower them in achieving applying their potential to build the organization competitive advantage.

Keywords: management, human resource, organization
\end{abstract}

\section{PENDAHULUAN}

Perkembangan dunia serta perubahan struktural yang terjadi di berbagai aspek, telah menimbulkan tantangan dan sekaligus peluang bagi perkembangan dunia bisnis. Satu hal yang merupakan prasyarat untuk dapat mengatasi tantangan yang ada dan memanfaatkan peluang bisnis yang timbul adalah dengan meningkatkan daya saing. Daya saing strategi dicapai jika sebuah perusahaan berhasil merumuskan serta menerapkan suatu strategi yang tepat. Saat ini berbagai organisasi berusaha untuk meningkatkan daya saingnya dengan membangun dan bersama-sama mencari sumber daya manusia yang dapat membawa kepada pembentukan perubahan paradigma tentang pentingnya keberadaan sumber daya manusia dalam suatu organisasi.

Berbagai pengaruh perubahan yang terjadi menuntut organisasi untuk membuka diri terhadap tuntutan perubahan dan berupaya menyusun strategi dan kebijakan yang selaras dengan perubahan lingkungan bisnis akan bergantung pada kemampuan organisasi dalam menyesuaikan diri terhadap lingkungan. Artinya, suatu organisasi mampu menyusun strategi dan kebijakan yang ampuh untuk mengatasi setiap perubahan yang terjadi. Keberhasilan penyusunan kebijakan dan strategi organisasi akan didukung lebih banyak fungsi manajerial yang ada. Salah satu bidang fungsional strategi yang menjadi perhatian adalah manajamen sumber daya manusia.

Manajemen sumber daya manusia merupakan bidang strategis dari organisasi. Manajemen sumber daya manusia harus dipandang sebagai perluasan dari pandangan tradisional untuk mengelola orang secara efektif dan untuk itu membutuhkan pengetahuan tentang perilaku manusia dan kemampuan untuk mengelolanya. Oleh sebab itu wajarlah apabila penyusunan strategi sumber daya manusia harus relevan terhadap penyusunan strategi bisnis. Tentu saja ini akan membutuhkan komitmen 
akan keterlibatan lebih tinggi dari sumber daya manusia.

Seputaran tahun 1960-an hingga saat ini, atmosfer organisasi telah berubah pesat. Berbagai arus kekuatan telah memicu perubahan-perubahan tersebut. Seiring dengan meningkatnya efek teknologi dan telekomunikasi yang telah berhasil "mengecilkan" ukuran dunia, pergerakan keragaman para pekerja (profesional) membawa nilai-nilai, perspektif dan ekspektasi yang berbeda di antara mereka (para pekerja). Kesadaran publik semakin lama semakin sensitif dan menuntut organisasi agar semakin profesional dan bertanggung jawab secara sosial. Seperti halnya negara-negara dunia ketiga, kita pun telah turut terlibat dalam persaingan pasar global dan melebarkan arena bagi aktivitas penjualan dan pelayanan.

Organisasi pun akhirnya kini tidak hanya dituntut untuk bertanggung jawab kepada pemilik dana atau pemegang saham, namun juga dituntut untuk bertanggung jawab kepada para stakeholders. Pada saat ini, dunia yang kita alami sudah sangat jauh berbeda dengan dunia yang kita alami sepuluh lima belas tahun yang lalu. Dunia ilmu juga tidak terlepas dari berbagai pengaruh ini. Terjadi perubahan era, yang sekarang kita berada era informasi, bukan lagi era industrialisasi. Era di mana pemikiran linear yang bersifat mekanistik, yang menghasilkan kemajuan seperti yang kita alami saat ini, sudah mulai digoncang oleh hasil-hasil perkembangan ilmu yang baru, yang mendorong tumbuhnya suatu paradigma baru.

\section{Paradigma Lama dan Baru}

Marilyn Ferguson (1993), dalam The New Paradigm: Emerging Strategic for Leadership and Organizational Change memberikan overview yang detail atas perbedaan yang terjadi antara paradigma lama dan baru seperti yang terlihat pada Tabel 1.
Berdasarkan pada perubahan paradigma tersebut, seharusnya peran pengelola sumber daya manusia berubah sebagaimana tuntutan zaman. Kondisi perubahan tersebut dapat digambarkan dalam sebuah contoh perlombaan perahu kayu dan perahu karet. Dalam lomba perahu kayu, masingmasing tim berlomba-lomba untuk mencapai tujuan yaitu mencapai finish tercepat. Kita pahami posisi masing-masing perahu dan cara kerja untuk menjalankan perahu tersebut. Pada tiap-tiap perahu, posisi anak buah berada di pinggir lambung perahu dan letaknya tertata rapi pada sisi kanan dan kiri, mereka diatur sedemikian rapi agar perahu dapat melaju dengan kencang. Demikian pula kita pahami posisi pemimpin, letaknya di depan anak buah/pegawai tetapi menghadap ke belakang dengan posisi ketinggian lebih dari posisi anak buah agar semua anak buah bisa melihat pimpinannya ketika memberi perintah dengan menggunakan genderang.

Menilik kondisi di atas, tentunya harus ada perubahan mendasar dalam memandang manusia yang ada di dalam organisasi. Terlebih dalam upaya peningkatan kualitas sumber daya manusia yang benar-benar menghasilkan generasi yang memiliki nilai profesionalitas yang tidak dapat diragukan. Bukan malah sebaliknya, yang menganggap nilai profesionalitas itu hanya untuk dijadikan sarana bagi suatu interes tertentu dari pihak ketiga. Bila memahami pandangan Parminedes dan Heraklitus serta dengan mendasarkan diri pada pandangan keilmuan dalam rumpun humaniora (ilmu psikologi adalah bagian di dalamnya) bahwa manusia harus menguasai alam, mendorong tumbuhnya ilmu-ilmu kealaman yang berusaha untuk "mengeksploitasi" alam demi pengembangan ilmu. Pandangan ini lebih mengedepankan ontologi ilmu adalah alam itu sendiri beserta seluruh isinya, dan manusia adalah bagian dari alam yang bertugas memberdayakan alam untuk pengembangan ilmu. Makna dari

Tabel 1. Perbedaan Paradigma Lama dan Baru Menurut Marilyn Ferguson

\begin{tabular}{|l|l|}
\hline \multicolumn{1}{|c|}{ Lama } & \multicolumn{1}{c|}{ Baru } \\
\hline Promote consumption at all cost & Appropriate consumption \\
\hline People to fit jobs & Jobs to fit people \\
\hline Imposed goal, top-down decision making & Autonomy encouraged, worker participation \\
\hline Fragmentation in work and roles & Identity transcends job description \\
\hline Clock model of company & Recognition of uncertainty \\
\hline Aggression, competition & Cooperation \\
\hline Work and play separate & Blurring of work and play \\
\hline Manipulation and dominance & Cooperation with nature \\
\hline Struggle for stability & Sense of change, of becoming \\
\hline Quantitative & Qualitative as well as quantitative \\
\hline Strictly economy motives & Spiritual values transcend material gain \\
\hline Polarized & Transcend polarities \\
\hline Short-sighted & Ecologically sensitive \\
\hline Rational & Rational and intuitive \\
\hline Emphasis on short-term solution & $\begin{array}{l}\text { Recognition that long-range efficiency must take in to } \\
\text { account harmonious work environment }\end{array}$ \\
\hline
\end{tabular}

Sumber: The New Paradigm: Emerging Strategic for Leadership and Organizational Change 
pengertian tersebut adalah menempatkan manusia sebagai individu yang "memiliki" alam bukan sebagai individu yang "dimiliki" alam.

Di lain pihak, dalam perkembangan ilmu psikologi terdapat ranah kajian pendalaman manusia di dalam organisasi yang lebih dikenal dengan konsep manajemen sumber daya manusia. Pada kajian ini manusia ditempatkan bukan lagi sebagai individu yang "memiliki" alam, tetapi menempatkan individu sebagai "aset" yang harus dimiliki untuk kegiatan produksi. Seringkali manusia di dalam organisasi dipandang sebagai "alat produksi" atau "aset", yang setara dengan aset lain yaitu uang, material, mesin, dan metode (dalam istilah manajemen lebih dikenal dengan nama $5 \mathrm{M}$ adalah man, money, material, machine, method). Bahkan pada perkembangan selanjutnya, pandangan manusia sebagai aset ini sampai harus dikalkulasi sedemikian rupa hingga untuk setiap program pengembangan manusia selalu dikaitkan dengan ROI (return on investment). Memperlakukan manusia sebagai aset harus dihitung-hitung untung ruginya, dalam hal ini manusia benar-benar dianggap sebagai kapital (human capital). Akhirnya, setiap rupiah yang dikeluarkan oleh organisasi/institusi harus disetarakan dengan investasi dan dihitung benar berapa tingkat ROI-nya.

\section{PEMBAHASAN}

\section{Manajemen Pengetahuan}

Secara umum manajemen pengetahuan (knowledge management) adalah suatu rangkaian kegiatan yang digunakan oleh organisasi untuk mengidentifikasi, menciptakan, menjelaskan, dan mendistribusikan pengetahuan untuk digunakan kembali, diketahui, dan dipelajari di dalam organisasi. Kegiatan ini biasanya terkait dengan objektif organisasi dan ditujukan untuk mencapai suatu hasil tertentu seperti pengetahuan bersama, peningkatan kinerja, keunggulan kompetitif, atau tingkat inovasi yang lebih tinggi.

Konsep manajemen pengetahuan ini meliputi pengelolaan sumber daya manusia (SDM) dan teknologi informasi (TI) dalam tujuannya untuk mencapai organisasi yang semakin baik, sehingga mampu memenangkan persaingan bisnis. Perkembangan teknologi informasi memang memainkan peranan yang penting dalam konsep manajemen pengetahuan. Hampir semua aktivitas kehidupan manusia akan diwarnai oleh penguasaan teknologi informasi, sehingga jika berbicara mengenai manajemen pengetahuan tidak lepas dari pengelolaan.

Adapun tahapan perkembangan manajemen pengetahuan dalam suatu organisasi meliputi:

1. Knowledge-chaotic (tak sadar konsep, tak ada proses informasi, dan tak ada sharing informasi);

2. Knowledge-aware (sadar akan kebutuhan manajemen pengetahuan, ada beberapa proses manajemen pengetahuan, ada teknologi, ada isu tentang sharing informasi);

3. Knowledge-enabled (memanfaatkan manajemen pengetahuan, mengadopsi standar, isu-isu berkaitan dengan budaya dan teknologi);

4. Knowledge-managed (kerangka kerja yang terintegrasi, merealisasikan manfaat, isu-isu pada tahap sebelumnya teratasi); dan

5. Knowledge-centric (manajemen pengetahuan merupakan bagian dari misi, nilai pengetahuan diakui dalam kapitalisasi pasar, manajemen pengetahuan terintegrasi dalam budaya).

\section{Peran SDM Dalam Konteks Membangun Budaya Pengetahuan}

Sumber daya manusia memegang peranan penting dalam membangun budaya yeng berpusat pada pengetahuan (knowledge-centric culture). Dalam hubungan ini, yang perlu diperankan oleh sumber daya manusia untuk menambah nilai adalah sebagai berikut (Linda Holbeche):

1. Fokus pada pembentukan struktur yang tepat;

2. Mengembangkan kepemimpinan fasilitatif;

3. Membangun infrastruktut teknologi informasi; dan

4. Membina hubungan dengan pemasok.

Pemikiran tentang perubahan fundamental dalam cara berorganisasi telah melahirkan pemikiran tentang manajemen perubahan. Menurut Maholtra (2000) istilah manajemen perubahan (change management) saat ini dipakai untuk mencakup teori dan praktek yang berhubungan dengan pengembangan organisasi (organizational development), sumber daya manusia, majemen proyek (project management), dan perubahan strategi organisasi.

Manajemen perubahan menjadi upaya perubahan organisasional yang lebih besar, bersama dengan komponen lain, yaitu pengembangan strategi, penyempurnaan proses bisnis, dan penerapan teknologi. Tujuan utamanya seringkali adalah mengintegrasikan komponen-komponen ini, misalnya dengan menciptakan kesetaraan antara penetapan tujuan-tujuan strategis dengan kebijakan sumber daya manusia, atau membangun infrastuktur teknologi informasi baru untuk mendukung terciptanya kerjasama antar kelompok. Manajemen perubahan sebenarnya juga merupakan penerapan teori yang menyatakan bahwa berpindah dari kondisi lama ke kondisi baru yang sesuai dengan masa depan memerlukan perubahan komprehensif dalam berbagai komponen, termasuk perilaku, kultur, struktur organisasi, proses kerja dan infrastuktur teknologi informasi

Bila dikaitkan dengan keberadaan sumber daya manusia suatu organisasi, maka tujuan utama dari manajemen perubahan adalah untuk mencapai sebuah keunggulan kompetitif dengan strategi yang kompetitif akan mempertinggi kinerja organisasi dan 
akan menjadi keunggulan dalam kompetitif (Sundar, dkk, 1993). Menurut Sundar, dkk (1993), organisasi yang mempunyai keunggulan kompetitif mempunyai aset-aset, nilai dan kecakapan yang unik terutama sumber daya manusia sebagai sumber daya keunggulan kompetitif. Dengan manusia sebagai operator utama, maka keunggulan kompetitif dapat menghasilkan implementasi strategi yang tidak dapat diimplementasikan oleh organisasi pesaing. Organisasi yang mempunyai keunggulan kompetitif akan mempunyai strategi yang lebih tinggi dari pesaing.

Terkait dengan kekuatan perubahan, organisasi didesak untuk mengadopsi "paradigma baru" atau melihat dunia saat ini secara lebih sensitif, fleksibel, dan mudah menyesuaikan diri dengan tuntutan dan harapan para stakeholders. Banyak sudah organisasi yang telah melepaskan atau sedang melepaskan paradigma lama yang bersifat top-down, kaku, dan berstruktur hierarkis menuju pada bentukbentuk yang "organik" (fluid). Dengan perkataan lain, diperlukan mindset yang baru, baik dalam pemahaman maupun pengelolaan organisasi dan manusia yang ada di dalamnya.

Era industrialisasi dimulai dengan ditemukannya mesin uap oleh James Watt. Penemuan ini menyebabkan digantikannya tenaga manusia dengan tenaga mesin. Terjadi pemisahan antara manusia yang bekerja dengan alat produksi. Hal ini mendorong tumbuhnya pabrik-pabrik, dengan segala macam konsekuensi pengelolaannya. Mesin menjadi suatu alat utama dalam proses produksi untuk meningkatkan kesejahteraan. Pentingnya mesin ini merasuki semua aspek kehidupan manusia sehingga cara berpikir dan cara bertindak kita menjadi mekanistis. Metafora mesin menjadi suatu metafora yang dominan dalam era industrialisasi.

Teknik pengelolaan yang dikembangkan dalam industrialisasi mengacu pada pandangan organisasi sebagai mesin dan memandang manusia sebagai salah satu bagian dari mesin (Morgan, G. 1998). Teknik-teknik mana-jemen yang berkembang dan mendominasi era industrialisasi dimulai dengan Scientific Management dari Taylor, yang berkembang lebih lanjut sesuai dengan tuntutan masyarakat antara lain Management by Objective (MBO), Management Science yang bersifat matematis untuk mengoptimalkan "mesin" organisasi, Total Quality Management yang berusaha meningkatkan kualitas keluaran organisasi, Bussiness Process Reenginerring [BPR] yang menekankan pada penghilangan proses-proses produksi yang tidak memberikan nilai tambah untuk meningkatkan efisiensi dan efektivitas organisasi.

Kata kunci yang dipegang dalam era ini adalah "efisiensi". Teknik motivasi dan teknik kepemimpinan yang berkembang dan dikembangkan dalam era ini juga menganggap manusia sebagai bagian dari alat produksi. Manusia harus dirangsang oleh sesuatu yang dari luar, extrinsic motivation, untuk berperilaku sesuai dengan keinginan organisasi seperti teknik motivasi yang dikemukakan oleh Vrom, Porter \& Lawler, teori Equity dari Adam. Teori-teori dan teknik-teknik kepemimpinan yang berkembang di era ini pun bersifat behaviouristik, yang menganggap manusia itu makhluk yang pasif, yang bisa digerakkan untuk kepentingan tertentu-dalam hal ini kepentingan organisasi. Teknik-teknik kepemimpinan dalam mengelola sumber daya manusia pada era ini berdasarkan pada dua sumbu utama, yaitu "sumbu tugas" dan "sumbu manusia". Dimulai dari model Ohio, dan dikembangkan lebih lanjut oleh University Michigan, menghasilkan berbagai teori dan model kepemimpinan seperti Managerial Grid dari Blake \& Mouton, Situational Leadership dari Hersey Blanchard, Path Goal theory dari House \& Mitchel, Contingency theory-LPC dari Fiedler, ataupun teori kepemimpinan Vroom, Yetton \& Jago yang semuanya lebih bersifat preskriptif.

Era informasi ini juga merubah drivers organisasi. Kepemilikan modal, sumber daya alam, tenaga kerja yang murah, mesin, dan teknologi tidak lagi menjamin bahwa organisasi akan mampu berkiprah dengan baik dalam suatu populasi organisasi. Era sekarang sangat mementingkan pemilikan dan penguasaan pengetahuan para anggota organisasi, sehingga driver utama bagi kelangsungan hidup organisasi adalah kepemilikan pengetahuan para anggotanya. Pengetahuan para anggota organisasi ini perlu dikelola lebih baik yang dikenal sebagai knowledge management. Nonaka membagi pengetahuan yang dimiliki organisasi menjadi dua yaitu tacit knowledge dan explicit knowledge. Tugas para pengelola organisasi adalah menjadikan tacit knowledge yang dimiliki anggota-anggotanya menjadi explicit knowledge yang dimiliki bersama. Organisasi dalam era ini membutuhkan knowledge workers. Untuk dapat survive, organisasi sebaiknya mengubah pola pengelolaan sumber daya manusia dalam organisasi, karena knowledge ini dimiliki oleh para anggota organisasi, dan akan keluar bersama anggota tersebut kalau dia meninggalkan organisasi. Bukan seperti mesin yang tetap tinggal dalam organisasi meskipun operatornya keluar dari organisasi.

Era knowledge economy membutuhkan karyawan-karyawan dan organisasi yang mampu melakukan proses pembelajaran secara terusmenerus, sehingga organisasi mampu menyesuaikan diri secara terus-menerus. Pembelajaran dalam organisasi tidak saja merupakan pembelajaran dari feedback negatif, yang disebut Argyris sebagai single loop learning, melainkan suatu proses pembelajaran yang dikenal sebagai double loop learning. Proses ini akan menghasilkan suatu learning organization.

Untuk menciptakan organisasi yang memiliki keunggulan kompetitif, pegawai harus menjadi agen perubahan, mempertajam proses dan budaya yang dapat meningkatkan kapasitas organisasi untuk berubah. Terdapat tiga tipe 
perubahan yaitu: pertama, perubahan inisiatif, memfokuskan pada penerapan program, proyek tahu prosedur baru. Kedua perubahan proses dalam organisasi dengan memfokuskan kepada cara bagaimana melakukan kerja sama optimal. Ketiga, perubahan budaya akan terjadi jika strategi dasar organisasi bisnis dikonseptualkan kembali. Keempat hal tersebut merupakan peran baru pegawai yang akan dapat meraih keunggulan kompetitif dengan kerja sama pimpinan atau manajer organisasi. Keunggulan kompetitif akan dicapai dengan tiga strategi yaitu: inovasi (innovation), peningkatan kualitas (quaity enhancement) serta penurunan biaya (cost reduction).

Terkait dengan dukungan kepada para pegawai, saat ini para pemimpin atau manajer organisasi/instansi harus berhadapan dengan arus perubahan yang cepat dan terus-menerus. Para pimpinan/manajer harus bekerja dengan pengambilan keputusan yang vital yang tidak dapat mengacu pada arah-arah pengembangan di masa yang lalu. Teknik-teknik manajemen harus secara berkesinambungan memperhatikan perubah-an di lingkungan dan organisasinya, meng-ukur perubahan dan mengelolanya. Mengelola perubahan tidak hanya berarti mengendalikan saja, namun juga mengadaptasinya atau bahkan mengarahkan sebagaimana mestinya. Tentu saja hal ini membuat para pimpinan/manajer tidak dapat menguasai seluruh pemecahan masalah atau sumber daya bagi setiap situasi. Manajer seyogyanya mulai mempertimbangkan dan lebih mendengar pada para pegawainya. Konsekuensinya, bentuk baru sebuah organisasi menjadi hal yang umum dilakukan seperti, worker-centered teams, self-organizing dan selfdesigning teams, dan sebagainya.

\section{PENUTUP}

Berdasarkan pada uraian di atas, dapat dipahami kalau perubahan paradigma dalam memperlakukan manusia (pegawai) di dalam organisasi sesuai dengan harkat dan martabatnya (memanusiakan) tidaklah mudah. Agar keberadaan mereka di dalam organisasi benar-benar diperlakukan bukan sebagai 'aset' alat produksi tetapi sebagai orang yang memiliki 'sesuatu' maka ada peran pimpinan dan pegawai yang saling melengkapi untuk merubahnya. Dalam hal ini, peran pimpinan sangat vital. Mereka telah menunjukkan komitmen perubahan dengan banyak mengorbankan waktu, tenaga dan biaya yang sangat besar. Komitmen inilah sebagai kunci keberhasilan menuju perubahan values (excellent with morality).

Di lain pihak, bila komitmen pimpinan tersebut tidak dibarengi dengan kesediaan pegawai untuk menggunakan waktu, kepercayaan, loyalitas, dan perilaku produktif maka proses perubahan akan tidak berjalan dengan baik (stagnant). Untuk itulah diperlukan pertemuan yang formal ataupun informal untuk menunjukkan pentingnya perubahan. Mengubah pola pikir pegawai akan arti pentingnya perubahan memang tidaklah mudah. Sebuah perubahan organisasi akan dapat berjalan baik, dengan memberikan waktu, kepercayaan, loyalitas dan perilaku produktif kepada pegawai, dan proses memperlakukan manusia sesuai dengan harkat martabatnya.

Dalam hal ini pegawai tidak dipandang sebagai alat produksi tetapi mereka adalah mitra sejawat yang seiring dalam menggapai perubahan organisasi demi menciptakan organisasi yang mampu kompetitif. Perubahan kehidupan masyarakat dalam berbagai bidangnya akibat globalisasi dan perkembangan teknologi informasi yang cepat memerlukan sikap adaptif sekaligus antisipatif. Mempersiapkan generasi muda bangsa yang berkualitas dan mempunyai harga diri, jelas merupakan suatu keharusan agar mereka dapat menghadapi berbagai tantangan yang terjadi sebagai dampak dari perubahan tersebut. Oleh karena itu, pendidikan nampaknya dapat menjadi salah satu cara mempersiapkannya. Dengan pendidikan, maka kualitas SDM dapat ditingkatkan, dengan pendidikan pengetahuan masyarakat dapat dikembangkan, sehingga mampu meningkatkan kapabilitas dirinya dalam menjalankan kehidupannya pada saat ini dan di masa datang.

\section{DAFTAR PUSTAKA}

Daft, Richard L., (2002) The Leadership Experience, 2ndEd. South Western Publ.Co, Ohio.

DeCenzo, A. Davis., Robbins, P. Stevens, (1994) Human Resource Management: Concept $\&$ Practices, 4 th edition, John Willey \& Sons, Inc, New York

Ferguson, Marilyn., (1993) The New Paradigm: Emerging Strategic for Leadership and Organizational Change., Michael Ray and Alan Rinzler, Eds., New Consciousness Reader.

Fishbein, M., and Ajzen, T (2004) The Influence of Attitude Behavior, Massachusetts University.

Malhotra, Yogesh (2000) "From Information Management to Knowledge Management: Beyond the 'Hi-Tech Hidebound Systems" dalam K. Srinantaiah dan MED Koenig (ed.), Knowledge Management for the Information Professional, Medford, NJ: Information Today Inc.

Sundar G., Baradwaj, Rajan Varadrajan, John Fahy (1993) Sustainable Competitive Advantage in Service Industries: A Conceptual Model and Research Proposition. Journal of Marketing. Vol.57. 
34 | Jurnal Bina Praja | Volume 4 Nomor 1 Edisi Maret 2012: 29 - 34 